\title{
Vitrification of immature bovine cumulus-oocyte complexes: effects of cryoprotectants, the vitrification procedure and warming time on cleavage and embryo development
}

\author{
Jennifer R Prentice-Biensch ${ }^{1,2}$, Jaswant Singh ${ }^{2}$, Reuben J Mapletoft ${ }^{3}$ and Muhammad Anzar ${ }^{1,2^{*}}$
}

\begin{abstract}
Background: The present studies evaluated the effects of cryoprotectants, the vitrification procedure and time in the warming solution containing sucrose on cleavage and embryo development of immature (GV stage) bovine cumulus-oocyte complexes (COCs).

Methods: Two experiments were conducted. In Experiment 1, COCs $(n=420)$ were randomly assigned to four groups: 1) Control group: no treatment; 2) VS1 group: COCs were exposed to vitrification solution 1 (VS1) containing 7.5\% ethylene glycol [EG] + 7.5\% dimethyl sulfoxide [DMSO] + 20\% calf serum [CS] in TCM-199 at 37 C for 5 min; 3) VS1 + VS2 group: COCs were exposed to VS1 for 5 min followed by VS2 (15\% EG + 15\% DMSO + 17.1\% sucrose $+20 \%$ CS) at 37 C for 45-60 sec; and 4) Vitrified group: COCs were exposed to VS1 and VS2, loaded on cryotops, vitrified in liquid nitrogen and then warmed in TCM-199+17.1\% sucrose + 20\% CS at 37 C for 1 min. In Experiment 2, COCs ( $n=581$ ) were assigned to the same groups, but those in VS1, VS1 + VS2 and Vitrified groups were sub-divided and exposed to the warming solution for either 1 or 5 min. After treatment and/or warming, all COCs in both experiments underwent in vitro maturation, in vitro fertilization and in vitro culture.

Results: Cleavage and blastocyst rates did not differ among Control, VS1 and VS1 + VS2 groups in either experiment. In Experiment 2, there was no effect of time in the warming solution.

However, both cleavage and blastocyst rates were lower $(P<0.001)$ in the Vitrified group than in the Control, VS1 and VS1 + VS2 groups (40.9 and 1.6\% vs 92.2 and 34.4\%, 79.4 and 25.2\%, and 80.2 and 20.8\%, respectively in Experiment 1, and 25.0 and $1.7 \%$ vs 75.3 and $27.2 \%, 67.9$ and $19.5 \%$, and 62.7 and 22.5\%, respectively in Experiment 2).
\end{abstract}

Conclusions: The permeating cryoprotectants (EG and DMSO) present in VS1 and VS2 solutions and the time in the warming solution containing sucrose had no adverse effects on cleavage and blastocyst rates of immature bovine COCs. However, cleavage rate and early embryo development were reduced following the vitrification and warming.

Keywords: Cattle, Cumulus-oocyte-complexes, Germinal vesicle stage, Cryoprotectants, Ethylene glycol, Dimethyl sulfoxide, Vitrification, Warming time, In vitro maturation, In vitro fertilization

\footnotetext{
* Correspondence: Muhammad.Anzar@agr.gc.ca

${ }^{1}$ Agriculture and Agri-Food Canada, Saskatoon Research Centre, Saskatoon, Saskatchewan, Canada

${ }^{2}$ Department of Veterinary Biomedical Sciences, Western College of Veterinary Medicine, University of Saskatchewan, Saskatchewan, Saskatoon, Canada

Full list of author information is available at the end of the article
}

\section{Biomed Central}

(c) 2012 Prentice-Biensch et al.; licensee BioMed Central Ltd. This is an Open Access article distributed under the terms of the Creative Commons Attribution License (http://creativecommons.org/licenses/by/2.0), which permits unrestricted use, distribution, and reproduction in any medium, provided the original work is properly cited. 


\section{Background}

Development of a reliable method for the cryopreservation of oocytes is important for assisted reproduction in human fertility clinics [1] and for conservation of female animal genetic resources [2-4]. Oocyte cryopreservation has been performed in several mammalian species; however, success rates have been low due to oocytes' unique structure and sensitivity to cooling [5]. Slow freezing and vitrification are two common methods of cryopreservation for mammalian oocytes and embryos. In conventional, slow (controlled) freezing, cells dehydrate because of increased salt concentrations in the extracellular compartment resulting in a reduced likelihood of intracellular ice formation, but this results in increased intracellular salt concentrations referred to as the "solution effect" which can also cause cell damage [6]. Alternately, vitrification exposes cells to relatively high concentrations of cryoprotectants and ultra-rapid cooling [7]. Vitrification is used to avoid chilling injury and ice crystal formation in the cryopreservation of tissue, embryos and oocytes [8-10]. Although vitrification does not require a sophisticated and expensive programmable cell freezer, and is a fairly quick procedure, it requires skill and experience.

Vitrification involves ultra-rapid cooling and results in glass formation due to high viscosity of the cryoprotectants in intra- and extra-cellular compartments [11,12]. Although mouse oocytes have been vitrified successfully [13], vitrification of bovine oocytes is challenging due to their complex structure and sensitivity to chilling [14]. Previously, we examined the effect of vitrification of bovine oocytes on nuclear maturation, cleavage and blastocyst development [15] and found that vitrified oocytes had reduced embryo developmental competence, as indicated by low blastocyst production rates $(<5 \%)$ compared to non-vitrified controls (31\%).

One of the biophysical factors causing cellular disruption during cryopreservation is intracellular ice formation. However, vitrification reduces or eliminates intracellular ice formation by using highly viscous cryoprotectant solutions at relatively high concentrations [12,16]. Ethylene glycol, propylene glycol, glycerol and dimethyl sulfoxide [17] are used as permeating cryoprotectants for oocyte vitrification. Despite the critical importance of cryoprotectants for avoiding ice crystal formation in oocytes, the high concentration of cryoprotectants required for vitrification may be toxic and may cause osmotic injury to the cells, leading to reduced developmental competence $[11,18]$. To investigate the reduced developmental competence of oocytes following vitrification, it is important to examine the individual components of the vitrification system. Therefore, we proposed to determine the role of high concentrations of cryoprotectants present in vitrification solutions on cleavage rate of vitrified bovine oocytes and subsequent embryo development.

Warming time is a function of the temperature of the warming solution, and the sample volume and thickness which affects heat transfer. During the warming process, the oocytes are brought to the same temperature as the warming solution at an extremely high rate. The exposure to the warming solution is essential not only for warming, but also for removing cryoprotectants and rehydrating the oocytes [19]. Oocyte swelling during warming is an important determining factor for survival as volume fluctuations affect the plasma membrane integrity and organization of the cytoskeleton [20]. When exposed to an isotonic solution directly, water diffuses into the cell more rapidly than the cryoprotectants flow out and osmotic swelling can occur beyond the volume limits of the oocyte, resulting in membrane damage [21]. Thus, the warming solution normally contains a nonpermeating cryoprotectant such as sucrose [22,23]. If the time in the warming solution is insufficient, cryoprotectants may not be completely removed; however, the appropriate time interval for vitrified oocytes in the warming solution is still unclear. With this background, we hypothesized that 1) the high concentrations of cryoprotectants used in vitrification procedures would have toxic effects on bovine cumulus-oocyte complexes (COCs), resulting in low cleavage and embryonic developmental rates, and 2) exposing vitrified COCs to the warming solution containing sucrose for a longer interval would improve cleavage and blastocyst production rates by permitting the complete removal of intracellular cryoprotectants. Therefore, the present studies aimed to investigate the effects of the exposure of bovine COCs to vitrification solutions, the vitrification procedure, and time in the warming solution on cleavage and subsequent embryo development following in vitro fertilization.

\section{Methods}

This study was approved by the Animal Care Committee and Animal Research Ethics Board, University of Saskatchewan, Saskatoon, Canada.

\section{Chemicals and supplies}

Dulbecco's phosphate buffered saline (DPBS), newborn calf serum (CS), TCM-199 and MEM non-essential amino acids were purchased from Invitrogen Inc. (Burlington, ON, Canada). Lutropin-V (LH) and Folltropin-V (FSH) were supplied by Bioniche Animal Health Inc. (Belleville, ON, Canada). Unless otherwise stated, all other chemicals and reagents were purchased from Sigma-Aldrich (Oakville, ON, Canada). 


\section{Collection and initial processing of $\mathrm{COCs}$}

Bovine ovaries were collected from a slaughterhouse and transported to the laboratory at approximately $25^{\circ} \mathrm{C}$ within $8 \mathrm{~h}$. Ovaries were washed in $0.15 \mathrm{M} \mathrm{NaCl}$ and extra-ovarian tissues were removed. The immature COCs at the germinal vesicle (GV) stage were aspirated from follicles (3-8 $\mathrm{mm}$ in diameter) using an 18-gauge needle attached to a $5 \mathrm{ml}$ syringe containing approximately $1.0 \mathrm{ml}$ of DPBS supplemented with $5 \%$ CS (v/v). The aspirated follicular fluid was pooled in $50 \mathrm{ml}$ conical tubes and allowed to settle. The COCs were located under a stereomicroscope at 10x magnification, washed 3 times in DPBS $+5 \%$ CS and those with more than three layers of compacted cumulus cells and uniform cytoplasm (Grade 1) were selected for further processing.

\section{Vitrification and warming procedures}

The COCs (GV stage) were vitrified by first equilibrating in vitrification solution 1 [VS1; TCM-199+7.5\% ethylene glycol (EG; v/v) + 7.5\% dimethyl sulfoxide (DMSO; $\mathrm{v} / \mathrm{v})+20 \% \mathrm{CS}$ ] for $5 \mathrm{~min}$ at $37 \mathrm{C}$. After equilibration, COCs were transferred through three $20 \mu \mathrm{l}$-drops of vitrification solution 2 [VS2; TCM-199 + 15\% EG (v/v) +15\% DMSO $(\mathrm{v} / \mathrm{v})+20 \%$ CS $(\mathrm{v} / \mathrm{v})+17.1 \%$ sucrose $(\mathrm{w} / \mathrm{v})]$ at $37 \mathrm{C}$ for $45-60 \mathrm{sec}[10,24]$. Five COCs were loaded on each cryotop (Kitazato Supply Co., Fujinomiya, Japan) under a stereomicroscope with minimum surrounding medium and immediately plunged into liquid nitrogen [9]. The COCs were warmed by immersing the cryotop in $2 \mathrm{ml}$ of the warming solution [TCM-199+20\% CS (v/v) and $17.1 \%$ sucrose $(\mathrm{w} / \mathrm{v})]$ in a $35 \mathrm{~mm}$ petri dish at $37^{\circ} \mathrm{C}$ for $1 \mathrm{~min}$. The COCs were then washed 3 times in DPBS supplemented with $5 \% \mathrm{CS}(\mathrm{v} / \mathrm{v})$ at $37^{\circ} \mathrm{C}$.

\section{In vitro maturation, fertilization and culture}

In vitro maturation, fertilization and culture procedures were conducted as previously described [15]. Briefly, the immature COCs (GV stage) were washed 3 times in maturation medium [TCM-199 supplemented with 5\% CS, $5 \mu \mathrm{g} / \mathrm{ml} \mathrm{LH}, 0.5 \mu \mathrm{g} / \mathrm{ml} \mathrm{FSH}$ and $0.05 \mu \mathrm{g} / \mathrm{ml}$ gentamicin]. For in vitro maturation (IVM), groups of $20 \mathrm{COCs}$ were placed in $100 \mu \mathrm{l}$ droplets of maturation medium, under mineral oil and incubated for $22 \mathrm{~h}$ at $38.5^{\circ} \mathrm{C}, 5 \%$ $\mathrm{CO}_{2}$ in air and saturated humidity. For in vitro fertilization $(I V F)$, semen from three fertile bulls (2 straws/bull) was thawed at $37 \mathrm{C}$ for $1 \mathrm{~min}$, pooled and washed through Percoll gradient (45\% and 90\%) [25]. After washing, spermatozoa were added to Brackett-Oliphant (BO) fertilization medium [26] to a final concentration $3 \times 10^{6}$ sperm $/ \mathrm{ml}$. Following IVM, groups of 20 mature COCs were washed 3 times in $\mathrm{BO}$ supplemented with $10 \%$ bovine serum albumin (BSA, w/v) and added to $100 \mu \mathrm{l}$ droplets of spermatozoa in $\mathrm{BO}$, under mineral oil. A parthenogenetic control group of COCs (metaphase II stage) was incubated with no sperm. After $18 \mathrm{~h}$ of co-incubation with spermatozoa at $38.5^{\circ} \mathrm{C}, 5 \% \mathrm{CO}_{2}$ in air and saturated humidity, cumulus cells and sperm attached to oocytes were mechanically removed via pipetting. The presumptive zygotes were washed 3 times through in vitro culture (IVC) medium consisting of CR1aa [5\% CS, 2\% BME essential amino acids (v/v), 1\% MEM nonessential amino acids (v/v), 1\% L-glutamic acid (v/v), 0.3\% BSA and $0.05 \mu \mathrm{g} / \mathrm{ml}$ gentamicin sulfate]. Then, 20-25 zygotes were transferred into $100 \mu \mathrm{lVC}$ droplets under mineral oil and incubated at $38.5^{\circ} \mathrm{C}$ under $5 \% \mathrm{CO}_{2}, 90 \% \mathrm{~N}_{2}, 5 \%$ $\mathrm{O}_{2}$ and saturated humidity. After $48 \mathrm{~h}$ in culture, the cleavage (2-8 cells) rate was recorded, and embryo culture was continued in the same droplets. Subsequently, the blastocyst (containing inner cell mass, trophoblast and blastocoel) rate was determined on Days 7, 8 and 9 (Day $0=$ day of $I V F$ ). Both cleavage and blastocyst rates were based on the total number of COCs (GV-Grade 1) used in each treatment.

\section{Experiment 1: Effects of cryoprotectants and vitrification on cleavage and embryo development}

The immature COCs (GV stage) were assigned randomly to the following four groups: 1) Control group COCs were held in DPBS supplemented with 5\% CS; 2) VS1 group - COCs were exposed to VS1 for $5 \mathrm{~min}$ and then placed in DPBS supplemented with 5\% CS; 3) VS1 + VS2 group - COCs were exposed to VS1 for 5 min followed by VS2 for $45-60 \mathrm{sec}$, and then placed in DPBS supplemented with 5\% CS; 4) Vitrified group COCs were exposed to VS1 for 5 min, VS2 for 45$60 \mathrm{sec}$, vitrified in liquid nitrogen using the cryotop method, warmed at $37^{\circ} \mathrm{C}$ in the warming solution containing $17.1 \%$ sucrose $(\mathrm{w} / \mathrm{v})$ for $1 \mathrm{~min}$ and transferred in DPBS supplemented with 5\% CS. After treatments, all COCs underwent $I V M, I V F$ and $I V C$ as described above. Cleavage and blastocyst rates were used as evaluation parameters. This experiment was replicated five times on different dates.

\section{Experiment 2: Effects of cryoprotectants, vitrification procedure, and time in the warming solution on cleavage and embryo development}

As in Experiment 1, COCs were randomly assigned to Control, VS1, VS1 + VS2 and Vitrified groups; however, the COCs in VS1, VS1 + VS2 and Vitrified groups were sub-divided and exposed to the warming solution containing $17.1 \%$ sucrose $(\mathrm{w} / \mathrm{v})$ for either 1 or $5 \mathrm{~min}$, followed by DPBS supplemented with 5\% CS. All COCs then underwent IVM, IVF and IVC. Cleavage and blastocyst rates were used as evaluation parameters. This experiment was replicated five times on different dates. 


\section{Statistical analysis}

Data were analyzed using Proc Glimmix in SAS ${ }^{\circledR}$ Enterprise Guide 4.2 [27]. Analyses were performed using randomized complete block design modeling binary distribution (for yes/no response variables) for cleavage and blastocyst rates. The effects of Control, VS1, VS1 + VS2 and Vitrification were examined for cleavage and blastocyst rates in Experiment 1. In Experiment 2, analyses were performed using $4 \quad$ x 2 factorial randomized complete block design. Replicate number (1 to 5), treatment ( 1 = control, $2=\mathrm{VS} 1,3=\mathrm{VS} 1+\mathrm{VS} 2,4=$ vitrified $)$, warming time $(1=1$ min warming time, $2=5$ min warming time) and binomial response $(1=$ cleavage or blastocyst, 2 = no cleavage or no blastocyst development) were recorded for each oocyte. Syntax of the SAS program was: Proc glimmix method=quad; class replicate treatment warming_time; model cleavage (event = "1") = treatment|warming_time / dist = bin link = logit; random intercept/ subject=replicate; run. If the P-value for treatment, warming_time or their interaction term from Type III sum of squares was $<0.05$, then "lsmeans treatment warming_time treatment"warming_time/ diff lines ilink or adjust = tukey" was added to the syntax for separation of group means.

\section{Results}

Experiment 1: Effects of cryoprotectants and vitrification on cleavage and embryo development

Data on the effects of exposure to vitrification solutions and vitrification on oocyte cleavage and embryo development are presented in Table 1 . The cleavage rate of oocytes in the Control (not exposed to cryoprotectants or cooling; 92.2\%), VS1 (79.4\%) and VS1 + VS2 (80.2\%) groups did not differ, but all were higher than in the Vitrified group (40.9\%; $P<0.001)$. Similarly, the blastocyst rate (\% of total number of oocytes that were vitrified) in the Control (34.4\%), VS1 (25.2\%) and VS1 + VS2 (20.8\%) groups did not differ, but all were higher $(P<0.001)$ than the Vitrified group (1.6\%).

Table 1 Effects of cryoprotectant exposure and vitrification on cleavage of bovine oocytes and subsequent embryo development (Experiment 1)

\begin{tabular}{lccc}
\hline Group & $\begin{array}{c}\text { GV } \\
\text { oocytes (n) }\end{array}$ & $\begin{array}{c}\text { Cleavage } \\
\text { rate n (\%) }\end{array}$ & $\begin{array}{c}\text { Blastocyst rate } \\
\text { n (\% of total) }\end{array}$ \\
\hline Control (non-exposed) & 90 & $83(92.2 \%)^{\mathrm{a}}$ & $31(34.4 \%)^{\mathrm{a}}$ \\
VS1 & 107 & $85(79.4 \%)^{\mathrm{a}}$ & $27(25.2 \%)^{\mathrm{a}}$ \\
VS1 + VS2 & 96 & $77(80.2 \%)^{\mathrm{a}}$ & $20(20.8 \%)^{\mathrm{a}}$ \\
Vitrified & 127 & $52(40.9 \%)^{\mathrm{b}}$ & $2(1.6 \%)^{\mathrm{b}}$ \\
P-value & & & \\
Cryoprotectant exposure & & 0.847 & 0.456 \\
\hline
\end{tabular}

Values with different superscripts $(a, b)$ in the same column differ $(P<0.05)$. VS1: Vitrification solution 1.

VS2: Vitrification solution 2.
Experiment 2: Effects of cryoprotectants, vitrification procedure, and time in the warming solution on cleavage and embryo development

Data on the effects of cryoprotectant exposure, vitrification and time in the warming solution on cleavage and blastocyst rates are presented in Table 2. Within treatment group, there was no effect of time in the warming solution on cleavage or subsequent embryo development. When data from the Vitrified group were analyzed separately for the effect of time in the warming solution (after excluding all other groups), there was also no effect on cleavage rate or blastocyst rate. Both cleavage and blastocyst rates (\% of total number of oocytes that were vitrified) in the Vitrified group (25.0 and $1.7 \%$, respectively) were lower $(P<0.001)$ than in nonvitrified Control (75.3 and $27.2 \%$, respectively), VS1 (67.9 and $19.5 \%$, respectively) or VS1 + VS2 (62.7 and $22.5 \%$, respectively) groups which did not differ from one another.

No cleavage or blastocyst development was observed in the parthenogenetic control group in either Experiment 1 or 2 .

\section{Discussion}

In order to achieve intracellular vitrification, there are three main requirements i.e., high concentrations of permeating cryoprotectants, ultra-rapid cooling and low sample volume. Alteration in any one of these

Table 2 Effects of cryoprotectant exposure, vitrification and time in the warming solution on cleavage of bovine oocytes and subsequent embryo development (Experiment 2)

\begin{tabular}{|c|c|c|c|}
\hline Group & $\begin{array}{c}\text { GV } \\
\text { oocytes (n) }\end{array}$ & $\begin{array}{l}\text { Cleavage } \\
\text { rate } \mathrm{n}(\%)\end{array}$ & $\begin{array}{c}\text { Blastocyst rate } \\
\text { n (\% of total) }\end{array}$ \\
\hline Control (non-exposed) & 81 & $61(75.3 \%)^{a}$ & $22(27.2 \%)^{a}$ \\
\hline \multicolumn{4}{|l|}{ VS1 } \\
\hline 1 min warming interval & 82 & $60(73.2 \%)^{a}$ & $16(19.5 \%)^{a}$ \\
\hline 5 min warming interval & 77 & $48(62.3 \%)^{a}$ & $15(19.5 \%)^{a}$ \\
\hline \multicolumn{4}{|l|}{$V S 1+V S 2$} \\
\hline 1 min warming interval & 87 & $52(59.8 \%)^{a}$ & $16(18.4 \%)^{a}$ \\
\hline 5 min warming interval & 82 & $54(65.9 \%)^{a}$ & $22(26.8 \%)^{a}$ \\
\hline \multicolumn{4}{|l|}{ Vitrified } \\
\hline 1 min warming interval & 74 & $22(29.7 \%)^{b}$ & $1(1.4 \%)^{b}$ \\
\hline 5 min warming interval & 98 & $21(21.4 \%)^{b}$ & $2(2.0 \%)^{b}$ \\
\hline \multicolumn{4}{|l|}{ P-value } \\
\hline Cryoprotectant exposure & & 0.202 & 0.205 \\
\hline Warming time & & 0.241 & 0.689 \\
\hline \multicolumn{2}{|c|}{ Cryoprotectant exposure ${ }^{*}$ warming time } & 0.381 & 0.687 \\
\hline
\end{tabular}

Values with different superscripts $(a, b)$ in the same column differ $(P<0.05)$. VS1: Vitrification solution 1.

VS2: Vitrification solution 2. 
components can affect the success of the vitrification process. High concentrations of cryoprotectants are used to increase the viscosity of intra- and extra-cellular solutions, which increases the glass transition temperature [28]. Ethylene glycol (EG) and DMSO are commonly used cryoprotectants in vitrification, but they are considered toxic due to their cell permeating nature and the high concentrations needed to induce vitrification [29]. Ultra-rapid cooling allows the addition of permeating cryoprotectants at lower concentrations reducing toxicity to the cells [30]. Decreasing the sample volume during the vitrification procedure increases the cooling rate which improves heat transfer [29].

In the present study, the most profound and consistent observation was that the high concentrations of cryoprotectants used (15\% EG and DMSO) had no adverse effect on cleavage and blastocyst production rates. Similarly, exposure of vitrified oocytes to the warming solution containing sucrose for $5 \mathrm{~min}$ did not affect cleavage and blastocyst production, as compared to $1 \mathrm{~min}$, regardless of group. On the contrary, vitrification of the GV stage oocytes affected cleavage rates and blastocyst rates profoundly following in vitro maturation and fertilization. In both experiments, the cleavage rates were significantly reduced in the Vitrified group and blastocyst rates were not only significantly reduced, but were exceptionally low. Although these experiments were not designed to determine the necessity of sucrose in the warming solution, it is difficult to imagine that the absence of sucrose in the warming solution could be anything but detrimental. Thus, we concluded that our vitrification procedure was deficient in one or more ways for the cryopreservation of germinal vesicle stage bovine oocytes.

In the current studies, cleavage and blastocyst production rates in the VS1 + VS2 group did not differ from that in the Control group (Table 1). This suggests that the 45-60 sec exposure time was not sufficient for permeating these cryoprotectants to penetrate inside the bovine oocytes [31], or if penetrated, DMSO and EG had no toxic effects on bovine oocytes. Although there is still considerable debate, published literature tends to confirm the likelihood that these cryoprotectants are not highly toxic. DMSO alone [32] or in combination with other cryoprotectants [33] has been used successfully for oocyte vitrification, and in at least one study [34], the exclusion of DMSO from vitrification solution resulted in lower survival rates of oocytes. However, it has also been reported that DMSO (used alone or in combination with EG) resulted in reduced developmental competence of oocytes $[11,18]$. In other studies, DMSO-free vitrification systems e.g., glycerol and propanediol [35,36], or ethylene glycol and sucrose [37-39], have provided promising results with oocytes [34].
An ultra-rapid cooling rate is generally considered as one of the requirements for successful vitrification. Recently, ultra-rapid warming has been reported to be more important than concentrations of cryoprotectants or cooling rate [40]. The optimal warming time for vitrified bovine oocytes is still unknown. However, exposing oocytes to the warming solution for $5 \mathrm{~min}$ as opposed to 1 min in Experiment 2 appeared to have no obvious benefit on subsequent embryo development. Therefore, $1 \mathrm{~min}$ appears to be a sufficient time in the warming solution. It is also noteworthy that exposure to the warming solution containing sucrose for either 1 or $5 \mathrm{~min}$ did not have any adverse effect in nonvitrified oocytes in the VS1 and VS1 + VS2 groups.

Osmotic stress resulting from exposure to high concentrations of cryoprotectants in vitrification solutions could cause oocytes to undergo dramatic volume changes during warming. In this regard, one of the most important factors affecting cell survival during dilution is excessive cell swelling. Water moves through the cell membrane more rapidly than cryoprotectants, and because of the high concentration of cryoprotectants remaining in the cell, swelling occurs. Oocytes have biological limits in their tolerance to the osmotic stress associated with high concentrations of cryoprotectants [23]. Volume fluctuations can affect the integrity of the plasma membrane as well as the cytoskeletal organization of oocytes [20]. During this process, oocytes are rehydrated while cryoprotectants and water are exchanged due to their gradients across the cell membrane [19]. For this reason, sucrose is commonly used in warming solution to counterbalance the osmotic shock during conventional freezing [22] and vitrification [23]. Although these experiments were not designed to determine the benefits of sucrose in the warming solution, there was no evidence for any adverse effects.

Bovine oocytes at different nuclear stages (germinal vesicle, metaphase I and metaphase II) have been cryopreserved successfully, using both slow freezing or vitrification methods. Mature oocytes have meiotic spindles that are extremely sensitive to cryoprotectant additives and cooling rates which result in tubulin depolymerization $[11,41,42]$. Therefore, immature oocytes (GV stage) enclosed in cumulus cells (COCs) were used in the current study. The role of cumulus cells during oocyte cryopreservation is still not clear. Cumulus cells provide a rigid structure to oocytes and thus protect them against osmotic shock during cryopreservation [43]. It has been reported that the survival, cleavage and blastocyst production rates of bovine oocytes were higher when vitrified with enclosed cumulus cells than partially denuded COCs [10], as cumulus cells support the oocyte during in vitro maturation and fertilization [44]. 
Cryopreservation of oocytes has been reported to result in several ultrastructural and morphological alterations including damage to the cell membrane and ooplasm, and abnormal distribution of chromosomes, microtubules and actin microfilaments [45-47]. Additionally, damage to gap junction integrity can result in disruption of the communication between cumulus cells and oocytes $[11,48]$. These morphological changes have been linked to a failure in fertilization and embryo development $[48,49]$. Consequently, the disruptions in protein synthesis, and the failure of cumulus cell expansion and further meiotic development may also be responsible for the failure of cleavage and subsequent embryo development following vitrification [50].

In a recent study, only $23 \%$ of vitrified COCs (GV stage) reached the MII stage following IVM as compared to $84 \%$ in nonvitrified control COCs [51]. In another study using similar vitrification conditions (15\% EG and DMSO in VS2, 45-60 sec exposure time and cryotop as a loading device), cleavage and blastocyst production rates were somewhat higher than in the present study, but still low [10]. It is noteworthy that in the present study, cleavage and blastocyst rates were based on the original number of oocytes (COCs) that were vitrified. Thus, data have been presented and interpreted very conservatively. Based on these results and published literature, we must conclude that the optimum vitrification procedure for GV stage oocytes has yet not been developed.

\section{Conclusions}

The brief exposure (45-60 sec) of immature (GV stage) bovine COCs to vitrification solutions (15\% of each EG and DMSO) did not adversely affect their subsequent cleavage and embryo development. There was no apparent cytotoxic effect and there was no evidence that osmotic stress was responsible for the low blastocyst production rates following vitrification. Furthermore, 5 min exposure to the warming solution had no added benefits over $1 \mathrm{~min}$, with regards to cleavage and blastocyst production rates. Collectively, data provide evidence suggesting that the vitrification procedure was responsible for the reduced cleavage and embryo development rates following vitrification and warming.

\footnotetext{
Abbreviations

COCs: Cumulus-oocyte complexes; GV: Germinal vesicle; VS: Vitrification solution; EG: Ethylene glycol; DMSO: Dimethyl sulfoxide; CS: Calf serum; TCM-199: Tissue Culture Medium-199; IIF: Intracellular ice formation; DPBS: Dulbecco's phosphate buffered saline; MEM: Minimum Essential Medium; IVM: In vitro maturation; IVF: In vitro fertilization; BO: Brackett-Oliphant; IVC: In vitro culture; BSA: Bovine serum albumin.
}

\section{Competing interests}

The authors declare that they have no competing interests.

\section{Authors' contributions}

JRP conducted the experiments, analyzed the data and wrote the draft of manuscript. JS designed the experiment, and analyzed the data and interpreted the results. RJM designed the experiment and revised the manuscript critically. MA designed and coordinated the whole study, interpreted the data, prepared the manuscript, acted as an MSc supervisor of JRP. All authors read and approved the final manuscript.

\section{Acknowledgements}

These studies were supported by the Canadian Animal Genetic Resource Program, Agriculture and Agri-Food Canada.

\section{Author details}

${ }^{1}$ Agriculture and Agri-Food Canada, Saskatoon Research Centre, Saskatoon, Saskatchewan, Canada. ${ }^{2}$ Department of Veterinary Biomedical Sciences, Western College of Veterinary Medicine, University of Saskatchewan, Saskatchewan, Saskatoon, Canada. ${ }^{3}$ Department of Large Animal Clinical Sciences, Western College of Veterinary Medicine, University of

Saskatchewan, Saskatchewan, Saskatoon, Canada.

Received: 26 April 2012 Accepted: 30 August 2012

Published: 6 September 2012

\section{References}

1. Hunter JE, Fuller BJ, Bernard A, Jackson A, Shaw RW: Vitrification of human oocytes following minimal exposure to cryoprotectants; initial studies on fertilization and embryonic development. Hum Reprod 1995, 10:1184-1188.

2. Hochi S, Kozawa M, Fujimoto T, Hondo E, Yamada J, Oguri N: In vitro maturation and transmission electron microscopic observation of horse oocytes after vitrification. Cryobiology 1996, 33:300-310.

3. Isachenko V, Alabart JL, Nawroth F, Isachenko E, Vajta G, Folch J: The open pulled straw vitrification of ovine GV-oocytes: positive effect of rapid cooling or rapid thawing or both? Cryo Letters 2001, 22:157-162.

4. Martino A, Pollard JW, Leibo SP: Effect of chilling bovine oocytes on their developmental competence. Mol Reprod Dev 1996, 45:503-512.

5. Massip A: Cryopreservation of bovine oocytes: current status and recent developments. Reprod Nutr Dev 2003, 43:325-330.

6. Mazur P: Cryobiology: the freezing of biological systems. Science 1970, 168:939-949.

7. Rall WF, Fahy GM: Ice-free cryopreservation of mouse embryos at $-196 \mathrm{C}$ by vitrification. Nature 1985, 313:573-575.

8. Abrishami M, Anzar M, Yang Y, Honaramooz A: Cryopreservation of immature porcine testis tissue to maintain its developmental potential after xenografting into recipient mice. Theriogenology 2010, 73:86-96.

9. Kuwayama M: Highly efficient vitrification for cryopreservation of human oocytes and embryos: the Cryotop method. Theriogenology 2007, 67:73-80.

10. Zhou XL, Al Naib A, Sun DW, Lonergan P: Bovine oocyte vitrification using the Cryotop method: Effect of cumulus cells and vitrification protocol on survival and subsequent development. Cryobiology 2010, 61:66-72.

11. Arav A, Shehu D, Mattioli M: Osmotic and cytotoxic study of vitrification of immature bovine oocytes. J Reprod Fertil 1993, 99:353-358.

12. Vajta G: Vitrification of the oocytes and embryos of domestic animals. Anim Reprod Sci 2000, 60-61:357-364

13. Nakagata N: High survival rate of unfertilized mouse oocytes after vitrification. J Reprod Fertil 1989, 87:479-483.

14. Fuku E, Kojima T, Shioya Y, Marcus GJ, Downey BR: In vitro fertilization and development of frozen-thawed bovine oocytes. Cryobiology 1992, 29:485-492.

15. Prentice JR, Singh J, Dochi O, Anzar M: Factors affecting nuclear maturation, cleavage and embryo development of vitrified bovine cumulus-oocyte complexes. Theriogenology 2011, 75:602-609.

16. Magnusson V, Feitosa WB, Goissis MD, Yamada C, Tavares LM, D'Avila Assumpcao ME, Visintin JA: Bovine oocyte vitrification: effect of ethylene glycol concentrations and meiotic stages. Anim Reprod Sci 2008, 106:265-273.

17. Pedro PB, Yokoyama E, Zhu SE, Yoshida N, Valdez DM Jr, Tanaka M, Edashige K, Kasai M: Permeability of mouse oocytes and embryos at various developmental stages to five cryoprotectants. J Reprod Dev 2005, 51:235-246 
18. Yamada C, Caetano HV, Simoes R, Nicacio AC, Feitosa WB, Assumpcao ME, Visintin JA: Immature bovine oocyte cryopreservation: comparison of different associations with ethylene glycol, gylcerol and dimethylsulfoxide. Anim Reprod Sci 2007, 99:384-388.

19. Schellander K, Peli J, Schmoll F, Brem G: Effects of different cryoprotectants and carbohydrates on freezing of matured and unmatured bovine oocytes. Theriogenology 1994, 42:909-915.

20. Agca Y, Liu J, Peter AT, Critser ES, Critser JK: Effect of developmental stage on bovine oocyte plasma membrane water and cryoprotectant permeability characteristics. Mol Reprod Dev 1998, 49:408-415.

21. Pedro PB, Zhu SE, Makino N, Sakurai T, Edashige K, Kasai M: Effects of hypotonic stress on the survival of mouse oocytes and embryos at various stages. Cryobiology 1997, 35:150-158.

22. Leibo SP, Mazur P: Methods for the preservation of mammalian embryos by freezing. In Methods in Mammalian Reproduction. Edited by J C, Daniel J. New York: Academic Press; 1978:179-201.

23. Liebermann J, Tucker MJ: Effect of carrier system on the yield of human oocytes and embryos as assessed by survival and developmental potential after vitrification. Reproduction 2002, 124:483-489.

24. Chian R, Kuwayama M, Tan L, Tan J, Kato O, Nagai T: High survival rate of bovine oocytes matured in vitro following vitrification. J Reprod Dev 2004, 50:685-696.

25. Parrish JJ, Krogenaes A, Susko-Parrish JL: Effect of bovine sperm separation by either swim-up or Percoll method on success of in vitro fertilization and early embryonic development. Theriogenology 1995, 44:859-869.

26. Brackett BG, Oliphant G: Capacitation of rabbit spermatozoa in vitro. Biol Reprod 1975, 12:260-274

27. SAS: SAS Enterprise Guide. 42nd edition. USA: Cary, NC; 2006

28. Pereira RM, Marques CC: Animal oocyte and embryo cryopreservation. Cell Tissue Bank 2008, 9:267-277.

29. Ledda S, Boglioli L, Succu S, Ariu F, Bebbere D, Leoni G, Naitana S: Oocyte cryopreservation: oocyte assessment and strategies for improving survival. Reprod Fertil Dev 2007, 19:13-23.

30. He X, Park EY, Fowler A, Yarmush ML, Toner M: Vitrification by ultra-fast cooling at a low concentration of cryoprotectants in a quartz microcapillary: a study using murine embryonic stem cells. Cryobiology 2008, 56:223-232

31. Checura CM, Seidel GE Jr: Effect of macromolecules in solutions for vitrification of mature bovine oocytes. Theriogenology 2007, 67:919-930.

32. Wani NA, Maurya SN, Misra AK, Saxena VB, Lakhchaura BD: Effect of cryoprotectants and their concentration on in vitro development of vitrified warmed immature oocytes in buffalo (Bubalus bubalis). Theriogenology 2004, 61:831-842.

33. Vieira AD, Mezzalira A, Barbieri DP, Lehmkuhl RC, Rubin MI, Vajta G: Calves born after open pulled straw vitrification of immature bovine oocytes. Cryobiology 2002, 45:91-94

34. Isachenko V, Montag M, Isachenko E, Dessole S, Nawroth F, van der Ven H: Aseptic vitrification of human germinal vesicle oocytes using dimethyl sulfoxide as a cryoprotectant. Fertil Steril 2006, 85:741-747.

35. Van Der Zwalmen P, Gaurois B, Ectors FJ, Touati K, Massip A, Ectors F: Some factors affecting successful vitrification of mouse blastocysts. Theriogenology 1988, 30:1177-1183.

36. Kuwayama M, Hamano S, Nagai T: Vitrification of bovine blastocysts obtained by in vitro culture of oocytes matured and fertilized in vitro. J Reprod Fertil 1992, 96:187-193.

37. Ali J, Shelton JN: Design of vitrification solutions for the cryopreservation of embryos. J Reprod Fertil 1993, 99:471-477.

38. Hurtt AE, Landim-Alvarenga F, Seidel GE Jr, Squires EL: Vitrification of immature and mature equine and bovine oocytes in an ethylene glycol, ficoll and sucrose solution using open-pulled straws. Theriogenology 2000, 54:119-128.

39. Papis $K$, Shimizu M, Izaike $Y$ : Factors affecting the survivability of bovine oocytes vitrified in droplets. Theriogenology 2000, 54:651-658.

40. Seki S, Mazur P: Ultra-rapid warming yields high survival of mouse oocytes cooled to $-196^{\circ} \mathrm{C}$ in dilutions of a standard vitrification solution. PLoS One 2012, 7:e36058

41. Lim JM, Ko JJ, Hwang WS, Chung HM, Niwa K: Development of in vitro matured bovine oocytes after cryopreservation with different cryoprotectants. Theriogenology 1999, 51:1303-1310.
42. Martino A, Songsasen N, Leibo SP: Development into blastocysts of bovine oocytes cryopreserved by ultra-rapid cooling. Biol Reprod 1996, 54:1059-1069

43. Park SE, Chung HM, Cha KY, Hwang WS, Lee ES, Lim JM: Cryopreservation of ICR mouse oocytes: improved post-thawed implantation development after vitrification using Taxol, a cytoskeleton stabilizer. Fertil Steril 2001, 75:1177-1184

44. Zhang L, Jiang S, Wozniak PJ, Yang X, Godke RA: Cumulus cell function during bovine oocyte maturation, fertilization, and embryo development in vitro. Mol Reprod Dev 1995, 40:338-344.

45. Men H, Monson RL, Parrish JJ, Rutledge JJ: Detection of DNA damage in bovine metaphase II oocytes resulting from cryopreservation. Mol Reprod Dev 2003, 64:245-250.

46. Saragusty J, Arav A: Current progress in oocyte and embryo cryopreservation by slow freezing and vitrification. Reproduction 2011, 141:1-19.

47. Stachowiak EM, Papis K, Kruszewski M, Iwanenko T, Bartomiejczyk T, Modlinski JA: Comparison of the level(s) of DNA damage using comet assay in bovine oocytes subjected to selected vitrification methods. Reprod Dom Anim 2008, 44:653-658.

48. Diez C, Duque P, Gomez E, Hidalgo CO, Tamargo C, Rodriguez A, Fernandez L, de la Varga S, Fernandez A, Facal N, Carbajo M: Bovine oocyte vitrification before or after meiotic arrest: effects on ultrastructure and developmental ability. Theriogenology 2005, 64:317-333.

49. Eroglu A, Toth TL, Toner M: Alterations of the cytoskeleton and polyploidy induced by cryopreservation of metaphase II mouse oocytes. Fertil Steril 1998, 69:944-957.

50. Im KS, Kang JK, Kim HS: Effects of cumulus cells, different cryoprotectants, various maturation stages and preincubation before insemination on developmental capacity of frozen-thawed bovine oocytes. Theriogenology 1997, 47:881-891.

51. Prentice J, Singh J, Anzar M: The effect of meiotic stage of bovine oocytes on the survival of vitrified cumulus oocyte complexes. In Annual Conference of the International Embryo Transfer Society; January 2012. Phoenix, Arizona, USA: Reprod Fertil Dev; 2012:135.

doi:10.1186/1477-7827-10-73

Cite this article as: Prentice-Biensch et al:: Vitrification of immature bovine cumulus-oocyte complexes: effects of cryoprotectants, the vitrification procedure and warming time on cleavage and embryo development. Reproductive Biology and Endocrinology 2012 10:73.

\section{Submit your next manuscript to BioMed Central and take full advantage of:}

- Convenient online submission

- Thorough peer review

- No space constraints or color figure charges

- Immediate publication on acceptance

- Inclusion in PubMed, CAS, Scopus and Google Scholar

- Research which is freely available for redistribution 